\title{
Research
}

\section{Impact of GP gatekeeping on quality of care, and health outcomes, use, and expenditure:}

\author{
a systematic review
}

\begin{abstract}
Background

GPs often act as gatekeepers, authorising patients' access to specialty care. Gatekeeping is frequently perceived as lowering health service use and health expenditure. However, there is little evidence suggesting that gatekeeping is more beneficial than direct access in terms of patient- and health-related outcomes
\end{abstract}

Aim

To establish the impact of GP gatekeeping on quality of care, health use and expenditure, and health outcomes and patient satisfaction.

\section{Design and setting \\ A systematic review.}

\section{Method}

The databases MEDLINE, PreMEDLINE, Embase, and the Cochrane Library were searched for relevant articles using a search strategy. Two authors independently screened search results and assessed the quality of studies.

\section{Results}

Electronic searches identified 4899 studies (after removing duplicates), of which 25 met the inclusion criteria. Gatekeeping was associated with better quality of care and appropriate referral for further hospital visits and investigation. However, one study reported unfavourable outcomes for patients with cancer under gatekeeping, and some concerns were raised about the accuracy of diagnoses made by gatekeepers. Gatekeeping resulted in fewer hospitalisations and use of specialist care, but inevitably was associated with more primary care visits. Patients were less satisfied with gatekeeping than direct-access systems.

\section{Conclusion}

Gatekeeping was associated with lower healthcare use and expenditure, and better quality of care, but with lower patient satisfaction. Survival rate of patients with cancer in gatekeeping schemes was significantly lower than those in direct access, although primary care gatekeeping was not otherwise associated with delayed patient referral. The long-term outcomes of gatekeeping arrangements should be carefully studied before devising new gatekeeping policies

\section{Keywords}

gatekeeping; healthcare expenditure; healthcare use; patient care; primary care; referral and consultation

\section{INTRODUCTION}

Gatekeeping in health care is a response to a shortage of specialists and a need to control healthcare expenditure. ${ }^{1}$ In gatekeeping systems, patients are required to visit a GP or primary care physician to authorise access to specialty care. However, the effectiveness of gatekeeping in controlling expenditure remains unclear On an individual patient level, one study of private health insurance found that mean annual total health expenditure was lower for patients with health insurance plans that required primary care gatekeeping to authorise specialist referrals than for those with an indemnity (non-gatekeeping) plan.? However, the percentage of gross domestic product spent on health does not differ significantly between countries with and without gatekeeping models of health care. ${ }^{3}$

A previous review, capturing literature up to January 2010, found that gatekeeping was related to lower health service use and lower health expenditure. However there was great variability in the magnitude and direction of the differences, and the impact on health-related and patientrelated outcomes was still inconclusive. The question remains whether gatekeeping is linked to any adverse health effects. A few studies have suggested that gatekeeping causes delayed diagnoses of cancer., ${ }^{5,6}$ In the UK - a healthcare system with strong gatekeeping - poor survival rates for breast, colorectal, and lung cancers compared with other European countries have been partly attributed to delayed diagnoses. ${ }^{6}$

Considering the potential impact of gatekeeping policy on patients and healthcare systems, ${ }^{3,5}$ there is a need for an updated systematic review to support healthcare policy. The aim of this study was to identify the effects of primary care physician gatekeeping on quality of care, health outcomes, use and expenditure, and physician and patient attitudes.

\section{METHOD}

A systematic review was conducted according to recommendations in the Cochrane Handbook for Systematic Reviews of Interventions, ${ }^{7}$ and reported according to the Preferred Reporting Items for Systematic Reviews and Meta-Analysis (PRISMA) statement. ${ }^{8}$

\section{Search strategy}

Following scoping searches, the strategy used in a previous systematic review ${ }^{4}$ was modified to include the term 'referral' to increase sensitivity to studies involving gatekeeping. Terms relating to primary care' were included to limit the search to gatekeeping in this setting. 'Quality of care',
P Sripa, MD, junior doctor and visiting researcher, Department of Primary Care and Public Health, School of Public Health, Imperial College London, London, UK; Department of Community Medicine, Faculty of Medicine, Khon Kaen University, Khon Kaen, Thailand. B Hayhoe, BSc, LLM, MD, MRCGP, DRCOG, DPMSA, clinical lecturer in primary care; A Majeed, MD, FRCP, FRCGP, FFPH, professor of primary care; $\mathbf{G}$ Greenfield, BA, MSc, PhD, research fellow in public heath, Department of Primary Care and Public Health, School of Public Health, Imperial College London, London, UK. P Garg, BHSc, MBChB, former medical student, Faculty of Medical and Health Sciences, University of Auckland, Auckland, New Zealand.

\section{Address for correspondence}

Geva Greenfield, Department of Primary Care and Public Health, School of Public Health, Imperial College London, 314 The Reynolds Building, St Dunstan's Road, London W6 8RP, UK

Email: g.greenfielddimperial.ac.uk

Submitted: 27 June 2018; Editor's response: 26 July 2018; final acceptance: 28 August 2018. (c)British Journal of General Practice

This is the full-length article (published online 26 Mar 2019) of an abridged version published in print. Cite this version as: Br J Gen Pract 2019; DOI: https://doi.org/10.3399/bjgp19X702209 


\section{How this fits in}

Previous work has suggested an association between gatekeeping and lower healthcare use and expenditure, with inconclusive evidence for the impact on health-related and patient-related outcomes. Particular concern exists that gatekeeping causes delayed cancer diagnosis. In this systematic review, gatekeeping was associated with lower healthcare use and expenditure, and better quality of care, but with lower patient satisfaction. Primary care gatekeeping was not otherwise associated with delayed patient referral.

'health expenditure', and 'health outcomes' and 'patient outcomes' were included to increase specificity.

The research databases MEDLINE, PreMEDLINE, Embase, and the Cochrane Library were searched for relevant studies. Preliminary searches showed that gatekeeping was rarely the main objective of a study. Therefore, a comprehensive search strategy was used from the databases respective inception dates up to September 2017. The MEDLINE search strategy is available from the authors on request.

\section{Eligibility criteria}

The eligibility criteria were discussed and agreed by all authors (Box 1). Gatekeeping was previously defined as a requirement to visit a primary care physician, family medicine doctor, GP, general internist, or general paediatrician in a primary care setting, ${ }^{4}$ so this definition was adopted. Studies relating to patient referrals in a primary care setting were included. Gatekeeping by a primary care physician, as an intervention, was required to be implemented in patient referrals. Studies considered were systematic reviews, experimental studies, and observational studies that included outcomes of quality of care, healthcare expenditure and use, health-related and patient-related outcomes including health-related quality of life, mortality, morbidity, and patient and clinician attitudes. Studies that were published in languages other than English and those for which the abstract or full-text could not be retrieved were excluded.

\section{Study selection}

Two of the authors independently screened titles and abstracts to identify eligible studies and conducted full-text screening for eligible studies. Discrepancies were solved through discussions with other authors.

\section{Data collection, extraction, and assessment of study quality}

Two authors independently extracted the following data from the studies: study design, setting, gatekeeping arrangements, population, duration, comparison, and outcomes of studies. The extracted information was collated in a structured form, and included information reported on the gatekeeping arrangement, categories of outcomes, country, study design, population, intervention, age group, conditions, sample size, comparison (if possible), and outcomes lquality of care, health expenditure, and health-related/patient-related outcomes). Extraction forms completed by the two authors were compared, and discrepancies were discussed with the other authors and followed up with reference to the original article.

\section{Risk of bias assessment}

The methodological quality of the studies was assessed independently by two authors following the Effective Practice for Organisation of Care recommendations for review authors. ${ }^{9}$ An appropriate assessment tool relevant for each study design was chosen: the AMSTAR checklist for quality assessment of systematic reviews and meta-analyse ${ }^{10}{ }^{10}$ the Cochrane Risk of Bias Tool for Randomised Controlled Trials, ${ }^{7}$ and the National Institute of Health and National Heart, Lung, and Blood Institute Quality Assessment Tool for Observational Cohort and Cross-Sectional Studies. ${ }^{11}$ The quality of each study was based on allocation, outcome assessment, data sources, and risk of contamination and bias. As quality assessment tools specific to each study design were used, the quality of studies with different designs was not compared.

\section{Data synthesis}

Owing to the variety of measured outcomes and methodological approaches in the included studies, it was not possible to conduct a meta-analysis, and therefore a descriptive narrative synthesis was used. ${ }^{12}$

\section{RESULTS}

\section{Study selection}

Electronic database searches yielded 8734 articles, of which 3835 were duplicates. Following title and abstract screening, 80 full-text studies were obtained. A total of 55 studies were excluded because they did not meet eligibility criteria, leaving 25 studies for analysis (Figure 1). 2,4,13-35 


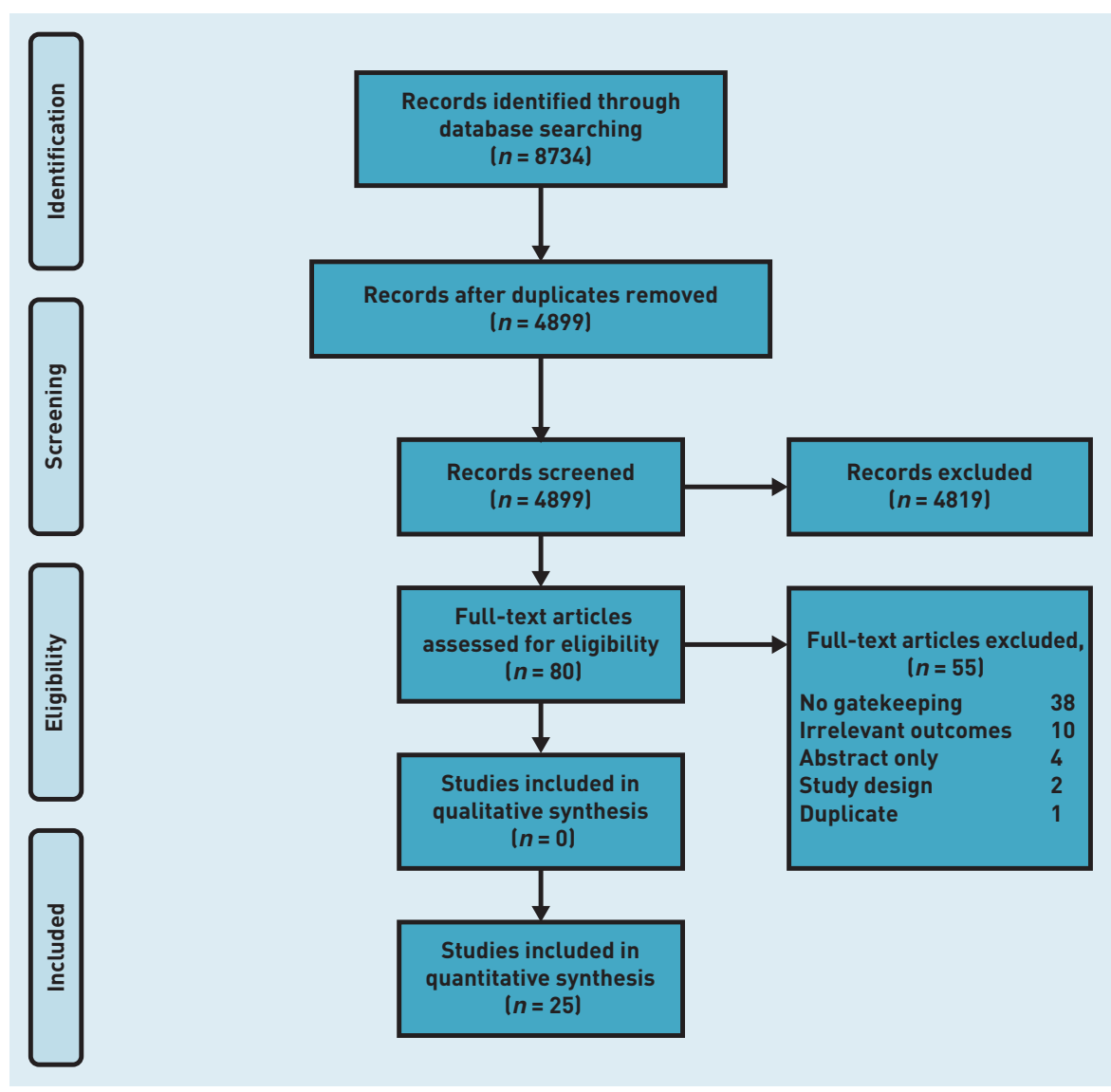

Figure 1. PRIMSA flow diagram for the search and selection process applied during the overview.

\section{Study characteristics}

Twenty-one observational studies, two controlled before-and-after studies, one systematic review, and one randomised controlled trial were included in the review; there were 17 studies from the US and eight from Europe, respectively (Table 1).2,4,13-35 Most of the studies included adult populations, and four included only children $1<18$ years old). Various health conditions were considered in the included studies. Mostly, the included studies examined the effects of gatekeeping interventions, including implementing or switching to a gatekeeping system, 17,18,22 access to cancer screening services, ${ }^{13,20,23}$ emergency departments, ${ }^{35}$ and surgical departments. ${ }^{14,16}$

\section{Risk of bias assessment}

Although most observational studies were of fair quality, 2,13,19-25,27,30,31,34 experimental studies were rated at high risk of bias on the selective reporting domains. . $^{17,18,32}$ One systematic review scored 7 out of 11 according to AMSTAR recommendations. The AMSTAR checklist for methodological assessment of systematic reviews reflects bias. $^{36}$ Another ecological study was not assessed because of its research design. ${ }^{15}$
Quality assessment for included studies is available from the authors on request.

\section{Impact of gatekeeping on various indicators}

Extracted outcomes from the studies are summarised in Table 2.

Quality of care. Five studies reported the impact of gatekeeping on outcome measures. In the US, patients were more likely to receive cardiac catheterisations (33\% versus $19 \% ; P<0.01)$ where there was primary care gatekeeping in place. ${ }^{31}$ Female patients enrolled in healthcare plans with gatekeeping were reported as having significantly more mammography screenings, clinical breast examinations, and cervical screening. ${ }^{13,23}$ They were reported as receiving more mammography in total $(P<0.001$; adjusted $\mathrm{OR}=1.18 ; 95 \%$ $\mathrm{Cl}=1.03$ to 1.36$).{ }^{20}$ However, two studies in the UK and the US indicated that primary care gatekeepers were correct in only $31 \% 16$ and $43.6 \%{ }^{14}$ of diagnoses.

Health outcomes. Regarding cancer care, an ecological study reported that relative 1-year survival was higher in a directaccess system than in a gatekeeping system among patients with cancer. ${ }^{15}$ However, a pilot study included in a previous review ${ }^{4}$ demonstrated no difference in melanoma outcomes between gatekeeping and direct access, although patients in the directaccess group underwent diagnostic biopsy sooner than those in the gatekeeping group.

Healthcare use. Ten studies found effects of gatekeeping on healthcare use. The previous systematic review suggested that gatekeeping resulted in less hospitalisation and specialist use. ${ }^{4}$ In the US, a longitudinal study reported a significant reduction in emergency visits of patients following introduction of a gatekeeping system..$^{35}$ Additionally, one randomised controlled trial reported that patients subject to gatekeeping decreased their healthcare use by 0.57 specialty visits and 0.14 hospitalisations per year more than patients with direct access. ${ }^{32}$

Patients made more visits to their primary care physician when gatekeeping was in place $(P=0.05) .{ }^{18}$ One cohort study reported that subspecialist visits declined in children with the gatekeeping (from 1.6/ year to 0.5/year; $P<0.0011 .{ }^{22}$ However, one retrospective study showed that patients with healthcare plans requiring gatekeeper authorisation had 33\% more total visits (primary care physician and specialist) than adults with a direct access plan. ${ }^{24}$ 


\section{Table 1. Characteristics of included studies}

\begin{tabular}{|c|c|c|c|c|c|c|}
\hline Study and year & Study design & Country & Participants & Age, years & Condition & Intervention \\
\hline Phillips et al (2004) & Observational & US & 13534 & $>18$ & Cancer screening & Gatekeeping plan \\
\hline $\begin{array}{l}\text { Mitchell and Keenan } \\
(2008)^{14}\end{array}$ & Observational & UK & 209 & $14-99$ & Surgical admission & GP referral \\
\hline $\begin{array}{l}\text { Vedsted and Olesen } \\
(2011)^{15}\end{array}$ & Ecological & $\begin{array}{l}19 \text { European } \\
\text { countries }\end{array}$ & 19 countries & $\mathrm{N} / \mathrm{A}$ & Cancer & Gatekeeping plan \\
\hline Hartzell et al (2013)16 & Observational & US & 200 & N/A & $\begin{array}{l}\text { Suspected hand surgical } \\
\text { condition }\end{array}$ & Gatekeeping plan \\
\hline Ferris et al (2002) ${ }^{17}$ & $\begin{array}{l}\text { Controlled } \\
\text { before-and-after }\end{array}$ & US & 59952 & $<18$ & $\mathrm{~N} / \mathrm{A}$ & Gatekeeping plan \\
\hline Pati et al (2005)² & Observational & US & 8195 & $18-65$ & N/A & $\begin{array}{l}\text { Managed care with } \\
\text { gatekeeping plan }\end{array}$ \\
\hline Ferris et al (2001) ${ }^{18}$ & $\begin{array}{l}\text { Controlled } \\
\text { before-and-after }\end{array}$ & US & 59997 & $>18$ & N/A & Without gatekeeping plan \\
\hline Escarce et al (2001) $)^{19}$ & Observational & US & 55954 & $18-64$ & $\mathrm{~N} / \mathrm{A}$ & HMO with gatekeeping plan \\
\hline Tye et al (2004) $)^{20}$ & Observational & US & 2909 & $>40$ & $\begin{array}{l}\text { Patients without a } \\
\text { history of breast cancer }\end{array}$ & Gatekeeping plan \\
\hline Linden et al (2003) $)^{21}$ & Observational & $\begin{array}{l}\text { The Netherlands } \\
\text { and Germany }\end{array}$ & 1140 & $15-65$ & $\begin{array}{l}\text { Suspected psychological } \\
\text { problems }\end{array}$ & Gatekeeping plan \\
\hline Ferris et al $(2001)^{22}$ & Observational & US & 1839 & $<18$ & $\mathrm{~N} / \mathrm{A}$ & Gatekeeping plan \\
\hline $\begin{array}{l}\text { Velasco Garrido et al } \\
(2011)^{4}\end{array}$ & $\begin{array}{l}\text { Systematic } \\
\text { review }\end{array}$ & Germany & 26 studies & N/A & N/A & Gatekeeping plan \\
\hline $\begin{array}{l}\text { Haggstrom et al } \\
(2004)^{23}\end{array}$ & Observational & US & 2623 & $18-65$ & $\begin{array}{l}\text { Mammography and } \\
\text { cervical screening }\end{array}$ & Gatekeeping plan \\
\hline Joyce et al (2000) $)^{24}$ & Observational & US & 53011 & $18-64$ & $\mathrm{~N} / \mathrm{A}$ & HMO with gatekeeping plan \\
\hline $\begin{array}{l}\text { Schneider et al } \\
(2016)^{25}\end{array}$ & Observational & Germany & 3616510 & $\geq 18$ & $\mathrm{~N} / \mathrm{A}$ & $\begin{array}{l}\text { Coordinated care with } \\
\text { gatekeeping plan }\end{array}$ \\
\hline $\begin{array}{l}\text { Kroneman et al } \\
(2006)^{26}\end{array}$ & Observational & $\begin{array}{l}18 \text { European } \\
\text { countries }\end{array}$ & 18 countries & N/A & $\mathrm{N} / \mathrm{A}$ & Gatekeeping plan \\
\hline Pati et al $(2003)^{27}$ & Observational & US & 3254 & $<18$ & $\mathrm{~N} / \mathrm{A}$ & Gatekeeping plan \\
\hline Delnoij et al (2000)28 & Observational & $\begin{array}{l}18 \text { OECD member } \\
\text { countries }\end{array}$ & 18 countries & N/A & $\mathrm{N} / \mathrm{A}$ & Gatekeeping plan \\
\hline $\begin{array}{l}\text { Schwenkglenks } \\
\text { et al }(2006)^{29}\end{array}$ & Observational & Switzerland & 1810 & $\geq 18$ & $\mathrm{~N} / \mathrm{A}$ & Gatekeeping plan \\
\hline Kapur et al (2000) $)^{30}$ & Observational & US & 55954 & $18-64$ & Co-payment requirement & HMO with gatekeeping plan \\
\hline Rask et al (1999) ${ }^{31}$ & Observational & US & 1414 & $\geq 30$ & $\begin{array}{l}\text { Patients with chest pain } \\
\text { who were referred or self- } \\
\text { referred to a cardiologist }\end{array}$ & Gatekeeping plan \\
\hline $\begin{array}{l}\text { Schillinger et al } \\
(2000)^{32}\end{array}$ & $\begin{array}{l}\text { Randomised } \\
\text { controlled trial }\end{array}$ & US & 2293 & Adult & $\begin{array}{l}\text { Required to have at least one } \\
\text { visit to PCPs within } 12 \text { months } \\
\text { and at least one visit to any } \\
\text { San Francisco general hospital } \\
\text { clinic within } 6 \text { months }\end{array}$ & Required gatekeeper \\
\hline Halm et al (1997)33 & Observational & US & 330 & N/A & N/A & Gatekeeping plan \\
\hline Forrest et al (2002) ${ }^{34}$ & Observational & US & 19415 & $18-64$ & $\mathrm{~N} / \mathrm{A}$ & $\begin{array}{l}\text { Primary care authorisation } \\
\text { for referral }\end{array}$ \\
\hline Franco et al (1997) 35 & Observational & US & 4766 & $0-13$ & $\begin{array}{l}\text { Visited emergency } \\
\text { department and been triaged } \\
\text { by a triage nurse or PCP }\end{array}$ & $\begin{array}{l}\text { Primary care gatekeeper } \\
\text { for emergency department }\end{array}$ \\
\hline
\end{tabular}

$H M O=$ health maintenance organisation. $N / A=$ not available. $O E C D=$ Organisation for Economic Co-operation and Development. $P C P=$ primary care physician.

Health expenditure. Nine studies investigated the impact of gatekeeping on health expenditure. A previous systematic review showed health expenditure was
6-80\% lower under gatekeeping than directaccess schemes. ${ }^{4}$ Two other studies also reported reduced healthcare expenditure where gatekeeping was in place, ${ }^{28}$ with 
Table 2. Extracted outcomes from included studies

\begin{tabular}{|c|c|}
\hline Study & Favouring gatekeeping \\
\hline Phillips et al (2004) ${ }^{13}$ & $\begin{array}{l}\text { Female patients in gatekeeper plans were more likely to } \\
\text { receive mammography screening ( } 77 \% \text { versus } 71 \%) \text {, } \\
\text { clinical breast examination ( } 87 \% \text { versus } 80 \% \text { ), and cervical } \\
\text { screening ( } 84 \% \text { versus } 74 \% \text { ). All comparisons, } P<0.001\end{array}$ \\
\hline
\end{tabular}

Mitchell and

Keenan $(2008)^{14}$

Vedsted and

Olesen $(2011)^{15}$

Hartzell et al (2013) ${ }^{16}$

Ferris et al (2002) $)^{17}$
Favouring direct access

A correct provisional diagnosis was stated in $43.6 \%$ of primary care diagnoses

Relative 1-year survival was higher compared with gatekeeper system (gatekeeper $=67.8$, without gatekeeper $=73.4 ; P=0.004$ )

The correct diagnosis was made $31 \%$ of the time when the patient had been seen by only a primary care provider $(P=0.4)$

Children visited a primary care physician an average of 2.16 times (95\% $\mathrm{Cl}=2.12$ to 2.19 ) per 6 -month period before the removal of gatekeeping and 2.05 times $(95 \% \mathrm{Cl}=2.01$ to 2.08 ) per 6-month period after the removal of gatekeeping.

After a stable baseline period, the percentages of all visits to eligible specialists averaged $10.8 \%$ during the year before removal of gatekeeping and $11.0 \%$ during the year after removal of gatekeeping $(P=0.29)$

Pati et al (2005) $\quad$ For gatekeeping enrolees, mean annual total expenditures were US\$1791 (SE = 140) compared with US\$1834 (SE = 90) for those non-gatekeeping plans $(P=0.81)$

Median per capita expenditures were higher for managed-care gatekeeping enrolees at US\$561 (SE = 21) versus US \$492 (SE = 22) for indemnity enrolees (not statistically significant)

For outpatient expenditures, the proportion of adults with any ambulatory care expenditure was higher among care gatekeeping enrolees than among indemnity enrolees $(76 \%$ versus $70 \%$; $P<0.05)$ expenditures would have been US\$1835 (SE = 18) for gatekeeping enrolees versus US\$1959 (SE = 19) for indemnity enrolees Adults enrolled in managed care gatekeeping plans on average paid about US $\$ 110$ less out of pocket than indemnity enrolees $(P<0.05)$

Ferris et al (2001)18

$(2001)^{19}$

Third-party payments for ambulatory services were about US $\$ 65$ greater for gatekeeping enrolees than for indemnity enrolees $(P<0.05)$

Adults visited a PCP an average of 1.21 times per 6-month period before the removal of gatekeeping and 1.19 times per 6 -month period after the removal of gatekeeping ( $P=0.05)$

After a stable baseline period, the average proportion of visits to eligible specialists as a percentage of all visits was $29.0 \%$ before the removal of gatekeeping and $29.6 \%$ during the year afterward $(P=0.39)$

Rates of visits to specialists were stable over the baseline period and did not change with the removal of gatekeeping

About $83 \%$ of enrolees in the gatekeeper plan used physician services annually, compared with $74 \%$ of enrolees in the POS plan ( $P<0.001)$

About $5.7 \%$ of gatekeeper $\mathrm{HMO}$ members and $4.5 \%$ of $\mathrm{POS}$ plan members had inpatient hospital stays each year $(P<0.001)$

$87 \%$ of enrolees in the gatekeeper HMO used some type of medical care annually, compared with $78 \%$ of enrolees in the POS plan $(P<0.001)$

Gatekeeper enrolees had 25\% higher expenditures for physician services ( $P<0.001), 23 \%$ higher inpatient hospital expenditures $(P<0.01), 30 \%$ higher outpatient hospital expenditures ( $P<0.001)$, $43 \%$ prescription drug expenditures $(P<0.001)$, and $41 \%$ higher expenditures for other services $(P<0.001)$ than people in the POS plan Total medical care expenditures were $29 \%$ higher in the gatekeeper $\mathrm{HMO}(P<0.001)$

Tye et al (2004) $\quad$ Female patients in gatekeeper plans were more likely to report receiving mammography $(77 \%$ versus $72 \%$; $P<0.001)$. The adjusted $\mathrm{OR}=1.18(95 \% \mathrm{Cl}=1.03$ to 1.36$)$

Linden et al (2003) $)^{21} \quad$ At 3 months' follow-up, the average total number of contacts between the enrolled patients and any other physicians in Germany was 4.56 per patient compared with 3.49 in the Netherlands
At the 12-month follow-up, hospital admissions were reported less often in Germany (15.7\%) than in the Netherlands (25.4\%; $P<0.005)$

Psychiatric medication is given twice as often in Germany as in the Netherlands (16\% versus $7 \%$ ) 


\section{Table 2 continued. Extracted outcomes from included studies}

\begin{tabular}{|c|c|c|}
\hline Study & Favouring gatekeeping & Favouring direct access \\
\hline \multirow[t]{5}{*}{ Ferris et al (2001) $)^{22}$} & $\begin{array}{l}\text { Mean total expenditures for children in the gatekeeping group } \\
\text { decreased } 53 \% \text { from US } \$ 486 \text { before switching to gatekeeping } \\
\text { to US\$180 in } 1994\end{array}$ & \\
\hline & $\begin{array}{l}\text { Visits to subspecialists also declined dramatically in the } \\
\text { gatekeeping group after the switch to gatekeeping (1.6/year } \\
\text { in } 1991 \text { and } 1992 \text { to 0.5/year in 1994) ( } P<0.001 \text { for difference) }\end{array}$ & \\
\hline & $\begin{array}{l}\text { Mean annual subspecialty expenditures decreased } 6 \% \text { in the } \\
\text { indemnity group and } 59 \% \text { in the gatekeeping group } \\
(P<0.001 \text { for difference) }\end{array}$ & \\
\hline & $\begin{array}{l}\text { Mean visits to subspecialists for children with chronic conditions } \\
\text { decreased } 57 \% \text { in the gatekeeping group while increasing } 31 \% \text { in } \\
\text { the indemnity group ( } P<0.005 \text { for difference) }\end{array}$ & \\
\hline & $\begin{array}{l}\text { Outpatient expenditures for primary care physician services } \\
\text { declined for both the indemnity }(5 \%) \text { and gatekeeping }(53 \%) \\
\text { groups over the period of the study ( } P<0.004 \text { for difference) }\end{array}$ & \\
\hline \multirow[t]{5}{*}{$\begin{array}{l}\text { Velasco Garrido } \\
\text { et al }(2011)^{4}\end{array}$} & $\begin{array}{l}\text { For quality of life, the study showed results favouring } \\
\text { gatekeeping in single items (pain and role limitations), but no }\end{array}$ & The studies showed decreased satisfaction under the gatekeeping plan \\
\hline & statistically significant differences in overall quality of life & \multirow{4}{*}{$\begin{array}{l}\text { The diagnosis of melanoma was made without delay significantly more } \\
\text { frequently in patients with free access, which, however, did not lead to any } \\
\text { differences in the tumour stage at diagnosis }\end{array}$} \\
\hline & $\begin{array}{l}\text { The studies with greater suitability suggest fewer } \\
\text { hospitalisations under gatekeeping }\end{array}$ & \\
\hline & $\begin{array}{l}\text { Overall, the results suggest lower use of specialist care } \\
\text { under gatekeeping }\end{array}$ & \\
\hline & $\begin{array}{l}\text { Most observations suggest 6-80\% lower expenditures } \\
\text { under gatekeeping }\end{array}$ & \\
\hline
\end{tabular}

Haggstrom et al (2004) $)^{23}$ Female patients in gatekeeper plans were more likely to receive screening mammography (77\% versus $71 \%$; $P<0.001)$ and cervical screening (84\% versus $74 \% ; P<0.001$ )

Joyce et al (2000) $)^{24}$

Gatekeeper HMO members had 35\% more PCP visits,

$28 \%$ more specialist visits, and $33 \%$ more total visits than people in the POS plan

\section{Schneider et al (2016) $)^{25}$ Averaging over age, the total difference per patient was -€9.65 (95\% $\mathrm{Cl}=-11.64$ to -7.67$)$, indicating lower costs for the gatekeeping model \\ The prescription of psychotropic medication, measured in terms of cost, was lower in the coordinated group with total difference per patient $=-€ 20.31(95 \% \mathrm{Cl}=-26.43$ to -14.46$)$ in favour of coordinated care for these patients}

Kroneman et al (2006) ${ }^{26}$

Pati et al $(2003)^{27}$
Countries with more providers directly accessible for patients showed a higher patient satisfaction with GP services (Pearson's $r=0.54 ; P=0.05$ )

The proportion of children with any ambulatory care expenditures was higher among gatekeeping plan enrolees compared with indemnity plan enrolees (78\% versus $74 \%$; $P<0.05$ )

Mean total per capita annual expenditures for children in gatekeeping versus indemnity plans differed by $<1 \%$ (US $\$ 887$ versus US $\$ 881$, respectively)

Third-party expenditures for ambulatory services were on average US\$45 greater for children enrolled in gatekeeping plans than for those in indemnity plans $(P<0.05)$

Delnoij et al (2000) $\quad$ On average, per capita health spending is lower in gatekeeping systems than in non-gatekeeping systems In countries with gatekeeping GPs, ambulatory care expenditure has increased less than in non-gatekeeping systems 


\section{Table 2 continued. Extracted outcomes from included studies}

\section{Study}

Schwenkglenks

et al (2006) $)^{29}$

Kapur et al (2000) 30

\section{Favouring gatekeeping}

Generally, health expenditure in gatekeeping group was lower

than fee-for-service plans (but not statistically significant)

\section{Favouring direct access}

Expenditures tended to be higher in the gatekeeper $\mathrm{HMO}$ than in the POS plan, although covariate adjustment considerably narrowed the gaps observed in the unadjusted data (711 versus 564)

Expenditures for PCPs' services were significantly higher in the gatekeeper $\mathrm{HMO}(P<0.001)$

Total physician expenditures were $4 \%$ higher in the gatekeeper $\mathrm{HMO}(P<0.05)$

Total physician expenditures were $9 \%$ higher in the gatekeeper plan with US\$10 co-payments for PCP and PCP-referred specialist visits than in the POS plan with US $\$ 10$ and US $\$ 15$ co-payments $(P<0.01)$

\begin{tabular}{ll}
\hline Rask et al (1999) 31 & The cardiology visit rate was significantly higher in the \\
& open-access group (5.8 per 1000 open-access members \\
& versus 3.3 per 1000 gatekeeper members; $P<0.01$ ) and \\
& lower rate of echocardiograms among the gatekeeper \\
& patients ( $21 \%$ versus $29 \% ; P<0.01$ ) \\
& Gatekeeper patients with known coronary atherosclerotic \\
& heart disease were more likely to receive cardiac catheterisations \\
& (33\% versus $19 \% ; P<0.01$ ) \\
& Gatekeeper patients as a group received cardiac catheterisation \\
& significantly sooner than did open-access patients $(P=0.05)$
\end{tabular}

Schillinger et al (2000) ${ }^{32}$ Patients in an intervention group had 0.14 fewer hospitalisations per year than a control group $(P=0.02,95 \% \mathrm{Cl}=-0.26$ to -0.03$)$, representing approximately $29 \%$ fewer hospitalisations

Patients in an intervention group decreased their specialty use by 0.57 visits per year more than a control group $(P=0.04$, $95 \% \mathrm{Cl}=-1.05$ to -0.01 )

Regarding coordination of care among ED patients ( $n=734)$, a greater percentage of patients in an experimental group returned to general medicine clinic within a month of an ED visit, when compared with control patients $(61 \%$ versus $52 \%$; $P<0.01)$

\begin{aligned} \hline Halm et al (1997) & Gatekeeping had a positive impact on preventive care $(26 \% \\ &$ positive versus $10 \%$ negative), and knowledge over patients \\ & overall care (33\% positive versus $8 \%$ negative) $(P \leq 0.01)$. The overall \\ & cost of care was favourably affected by gatekeeping $(P<0.001)\end{aligned}$

Forrest et al (2002) $)^{34}$

Quality of care judged to be impacted negatively (20\% negative versus $6 \%$ positive; $P<0.001$

Gatekeeping was judged to have a negative effect on the appropriate use of hospitalisation (-0.33), laboratory tests (-0.22), specialists $(-0.45)$, and medication choice $(-0.45)(P<0.001)$

There is a significant difference in choice of PCP satisfaction between with and without authorisation requirement $167.1 \%$ versus $70.8 \%$, difference $=-3.7 ;$ P $>0.001)$

$E D=$ emergency department. $\mathrm{HMO}=$ health maintenance organisation. $\mathrm{OR}=$ odds ratio. $\mathrm{Cl}=$ confidence interval. $\mathrm{PCP}=$ primary care physician. $\mathrm{POS}=$ point of service SE $=$ standard error.

lower costs than fee-for-service systems. ${ }^{29}$

A cross-sectional study reported that total mean expenditure was US\$1835 for patients in a gatekeeping plan versus US\$1959 for direct-access patients, and the gatekeeping patients paid US\$110 less out-of-pocket. $^{2}$ Moreover, the total cost difference per patient was -€9.65 $195 \%$ $\mathrm{Cl}=-11.64$ to -7.67$)$, indicating lower costs for the gatekeeping model. ${ }^{25}$ However, a cross-sectional study in the US showed adults with a gatekeeping plan had 29\% higher total medical expenditure. ${ }^{19}$ Another study suggested that total physician 
expenditure in a gatekeeping plan was $4 \%$ higher $(P<0.05)$, especially for primary care physicians' services $(P<0.001) .{ }^{30}$

Healthcare expenditure for children was higher for those enrolled in a gatekeeping plan. ${ }^{27}$ However, if all enrolees had similar characteristics, total mean expenditure per capita would have been $4 \%$ lower for children with a gatekeeping plan. ${ }^{27}$ Similarly, another study in the US found total expenditure among children who switched to a gatekeeping plan from a direct-access plan decreased from US\$486 to US\$180.22

Physician attitudes. One cross-sectional study reported that primary care physicians perceived that gatekeeping had a negative impact on quality of care, and a positive impact on preventive care and knowledge of patients' overall care. ${ }^{33}$ Primary care physicians reported that gatekeeping was significantly better at cost control than direct access. However, they believed that gatekeeping had a negative effect on the appropriate use of hospitalisation, laboratory tests, specialists, and medication choice. ${ }^{33}$

Patient satisfaction. Gatekeeping was associated with reduced patient satisfaction compared with a direct-access system. One study reported that patients were more satisfied with primary care physicians in a direct-access system than in a gatekeeping system. ${ }^{34}$ Similarly, a European study found that countries with more directly accessible providers showed greater patient satisfaction with GP services. ${ }^{26}$

\section{DISCUSSION}

\section{Summary}

Included studies suggest an association between gatekeeping and better quality of care, especially in terms of preventive care, and appropriate referral for specialty care and investigation. However, one study reported unfavourable outcomes of patients with cancer under gatekeeping, ${ }^{15}$ and some raised concerns about the ability of GP gatekeepers to provide a correct diagnosis. ${ }^{14,16}$ Gatekeeping resulted in fewer hospitalisations $4,29,32$ and lower specialist use, $4,22,31$ but in more primary care visits. ${ }^{24}$ Whereas some studies show that gatekeeping has lower healthcare use and expenditure, 2,4,22,25,27-29,35 others suggest that gatekeeping has higher ambulatory care and outpatient expenditure.,27 Primary care clinicians have conflicting views on gatekeeping, ${ }^{33}$ whereas patients are often less satisfied with gatekeeping schemes, preferring direct access to specialists. 4,26,34

\section{Strengths and limitations}

This study aimed to summarise the current literature on an important mechanism shaping the functions of primary and secondary care, and the divide between them. It focused specifically on the gatekeeping function of primary care. The authors acknowledge that even this term has different meanings in different countries, under different healthcare models, and with different health insurance schemes, which makes comparison between studies challenging. Most of the studies included in this review are based in the US and so reflect the American healthcare system.

Although most included studies focused on gatekeeping interventions and impact on health outcomes, there may be some effects from other confounders such as cancer screening programmes, socioeconomic statuses, employments, and types of insurances that this study was unable to identify. Furthermore, the scarcity of randomised controlled trials make it challenging to attribute the observed differences merely to gatekeeping, because many other factors, such as different payment arrangements, could have affected the outcomes.

Most studies report process measures such as use, screening, or number of visits, with few reporting on patient-related and health-related outcomes, making it difficult to draw firm conclusions about the impact of gatekeeping on these areas. Finally, the findings are described in separate categories, derived from the included studies. It is likely that there is considerable inter-relation between these categories, with significant overlap, for example, between 'quality of care' and 'patient experience'. Similarly, there is likely to be a complex association between patient satisfaction, gatekeeping, and healthcare use. However, the nature of the studies as reported meant that it was not possible to gain a clearer understanding of these complexities.

\section{Comparison with existing literature}

Some authors have challenged the notion of gatekeeping as an effective costcontainment system. ${ }^{3,27}$ The findings show that gatekeeping often results in lower health expenditure and health use for health services because it controls costs associated with unnecessary expensive specialist care and resource use. ${ }^{37}$

Patients are often less satisfied with gatekeeping schemes and prefer direct access to specialists, because 
they believe that specialists have better facilities, and because they wish to see a specialist quicker. ${ }^{38,39}$ To improve patient satisfaction, health systems should enlarge primary care capacity and decrease the gap between primary and secondary care sectors, promoting the role of primary care professionals as "healthcare coordinators between primary and secondary care. ${ }^{38,39}$

Patients in gatekeeping schemes are more likely to have preventive care in the form of cancer screening including cervical screening and mammography. However, delayed diagnosis caused by gatekeeping is believed to be one of the factors causing lower cancer survival rates in the UK. In England, nearly three-quarters of patients with cancer who visited their GPs in $2002^{40}$ and $2014^{41}$ were referred to a specialist after only one or two consultations, and about $60 \%$ of all referred patients saw a specialist within 2 weeks. ${ }^{40,41}$ This suggests that, at least in the UK, delayed diagnosis of cancer is not caused solely by gatekeeping. but by other healthcare system factors, patient behaviour, and healthcare provider factors. $15,42-46$

\section{Funding}

This research was supported by the National Institute for Health Research (NIHR) Collaboration for Leadership in Applied Health Research and Care Northwest London (CLAHRC NWL). The views expressed in this article are those of the authors and not necessarily those of the NHS, the NIHR, or the Department of Health and Social Care. Poompong Sripa was supported by the Prince Mahidol Award Youth Programme. The funders have no role in shaping or drafting the manuscript.

\section{Ethical approval}

Ethical approval was not required for this study.

\section{Provenance}

Freely submitted; externally peer reviewed.

\section{Competing interests}

The authors have declared no competing interests.

\section{Acknowledgements}

The authors wish to thank Rebecca Jones, a specialist librarian, for her support in setting up the search strategy and retrieving the search results.

\section{Discuss this article}

Contribute and read comments about this article: bjgp.org/letters leading to worse patient outcomes.
The intended and unintended
consequences of setting up gatekeeping, relaxation of gatekeeping, and use of gatekeeping should be considered in services such as investigations, and preventive and supportive services. For example, relaxation of gatekeeping may be a good strategy to improve health outcomes and patient satisfaction, but can potentially increase waiting time to secondary care. ${ }^{40,41}$

Difficulties in comparing studies and healthcare systems make it hard to draw firm conclusions from these results about the impact of gatekeeping on the outcomes examined. In particular, the long-term impact on quality of care and health outcomes remains unclear. Further studies are required to understand the impact of gatekeeping arrangements on these factors.

Continued financial and logistical challenges for healthcare systems mean that a model with potential to reduce healthcare use and expenditure while potentially improving quality of care is highly attractive. Consequently, primary care gatekeeping remains embedded in the culture of health care in many countries, including the UK. However, as this review demonstrates, the evidence of its impact on healthcare systems and patients remains far from clear and is complicated by the heterogeneity of systems and studies. Although gatekeeping may be associated with a reduction in specialist healthcare use and resulting financial benefits, a possible association with delayed diagnosis, particularly in the context of cancer care, is of significant concern. Although further research into longer-term patient- and health-related outcomes of gatekeeping would be of value, policymakers should perhaps focus more on collaborative efforts in primary and secondary care, aiming for a more unified approach to patient care. (1) 


\section{REFERENCES}

1. Loudon I. The principle of referral: the gatekeeping role of the GP. Br J Gen Pract 2008; DOI: https://doi.org/10.3399/bjgp08X277113.

2. Pati $S$, Shea $S$, Rabinowitz D, Carrasquillo 0 . Health expenditures for privately insured adults enrolled in managed care gatekeeping versus indemnity plans. Am J Public Health 2005; 95(2): 286-291.

3. Greenfield G, Foley K, Majeed A. Rethinking primary care's gatekeeper role. BMJ 2016; 354: i4803.

4. Velasco Garrido M, Zentner A, Busse R. The effects of gatekeeping: a systematic review of the literature. Scand J Prim Health Care 2011; 29(1): 28-38.

5. Hawkes N. The role of NHS gatekeeping in delayed diagnosis. BMJ 2014; 348: g2633.

6. Richards MA. The size of the prize for earlier diagnosis of cancer in England. $\mathrm{Br}$ $J$ Cancer 2009; 101(Suppl 2): S125-S129

7. Higgins JPT, Green S, eds. Cochrane handbook for systematic reviews of interventions. Version 6 [updated September 2018]. 2011. https://training. cochrane.org/handbook (accessed 13 Feb 2019).

8. Liberati A, Altman DG, Tetzlaff J, et al. The PRISMA statement for reporting systematic reviews and meta-analyses of studies that evaluate healthcare interventions: explanation and elaboration. BMJ 2009; 339: b2700.

9. Cochrane Effective Practice and Organisation of Care (EPOC). EPOC resources for review authors. 2017. http://epoc.cochrane.org/epoc-specific-resourcesreview-authors (accessed 12 Feb 2019).

10. Shea BJ, Grimshaw JM, Wells GA, et al. Development of AMSTAR: a measurement tool to assess the methodological quality of systematic reviews. BMC Med Res Methodol 2007; 7: 10

11. National Institute of Health, National Heart, Lung, and Blood Institute. Study Quality Assessment Tools. Quality assessment tool for observational cohort and cross-sectional studies. https://uww.nhlbi.nih.gov/health-topics/study-qualityassessment-tools (accessed 18 Mar 2019).

12. Mays N, Pope C, Popay J. Systematically reviewing qualitative and quantitative evidence to inform management and policy-making in the health field. $J$ Health Serv Res Policy 2005; 10(Suppl 1): 6-20.

13. Phillips KA, Haas JS, Liang SY, et al. Are gatekeeper requirements associated with cancer screening utilization? Health Serv Res 2004; 39(1): 153-178.

14. Mitchell A, Keenan RA. Are Grampian general practitioners good gatekeepers for access to emergency general surgical care? Scott Med J 2008; 53(3): 33-35.

15. Vedsted P, Olesen F. Are the serious problems in cancer survival partly rooted in gatekeeper principles? An ecologic study. Br J Gen Pract 2011; DOI: https://doi. org/10.3399/bjgp11X588484.

16. Hartzell TL, Shahbazian JH, Pandey A, et al. Does the gatekeeper model work in hand surgery? Plast Reconstr Surg 2013; 132(3): 381e-386e.

17. Ferris TG, Chang Y, Perrin JM, et al. Effects of removing gatekeeping on specialist utilization by children in a health maintenance organization. Arch Pediatr Adolesc Med 2002; 156(6): 574-579

18. Ferris TG, Chang Y, Blumenthal D, Pearson SD. Leaving gatekeeping behind: effects of opening access to specialists for adults in a health maintenance organization. N Engl J Med 2001; 345(18): 1312-1317.

19. Escarce JJ, Kapur K, Joyce GF, Van Vorst KA. Medical care expenditures under gatekeeper and point-of-service arrangements. Health Serv Res 2001; 3616 Pt 1): 1037-1057.

20. Tye S, Phillips KA, Liang SY, Haas JS. Moving beyond the typologies of managed care: the example of health plan predictors of screening mammography. Health Serv Res 2004; 39(1): 179-206.

21. Linden $M$, Gothe $H$, Ormel J. Pathways to care and psychological problems of general practice patients in a 'gate keeper' and an 'open access' health care system: a comparison of Germany and the Netherlands. Soc Psychiatry Psychiatr Epidemiol 2003; 38(12): 690-697.

22. Ferris TG, Perrin JM, Manganello JA, et al. Switching to gatekeeping: changes in expenditures and utilization for children. Pediatrics 2001; 108(2): 283-290.

23. Haggstrom DA, Phillips KA, Liang SY, et al. Variation in screening mammography and Papanicolaou smear by primary care physician specialty and gatekeeper plan (United States). Cancer Causes Control 2004; 15(9): 883-892.
24. Joyce GF, Kapur K, Van Vorst KA, Escarce JJ. Visits to primary care physicians and to specialists under gatekeeper and point-of-service arrangements. Am J Manag Care 2000; 6(11): 1189-1196.

25. Schneider A, Donnachie E, Tauscher M, et al. Costs of coordinated versus uncoordinated care in Germany: results of a routine data analysis in Bavaria. BMJ Open 2016; 6(6): e011621.

26. Kroneman MW, Maarse $\mathrm{H}$, van der Zee J. Direct access in primary care and patient satisfaction: a European study. Health Policy 2006; 76(1): 72-79.

27. Pati S, Shea S, Rabinowitz D, Carrasquillo O. Does gatekeeping control costs for privately insured children? Findings from the 1996 medical expenditure panel survey. Pediatrics 2003; 111(3): 456-460.

28. Delnoij D, Van Merode G, Paulus A, Groenewegen P. Does general practitioner gatekeeping curb health care expenditure? J Health Serv Res Policy 2000; 5(1): 22-26.

29. Schwenkglenks M, Preiswerk G, Lehner R, et al. Economic efficiency of gatekeeping compared with fee for service plans: a Swiss example. J Epidemiol Community Health 2006; 60(1): 24-30.

30. Kapur K, Joyce GF, Van Vorst KA, Escarce JJ. Expenditures for physician services under alternative models of managed care. Med Care Res Rev 2000; 57(2): 161-181.

31. Rask KJ, Deaton C, Culler SD, et al. The effect of primary care gatekeepers on the management of patients with chest pain. Am J Manag Care 1999; $\mathbf{5 ( 1 0 ) :}$ 1274-1282.

32. Schillinger D, Bibbins-Domingo $K$, Vranizan $K$, et al. Effects of primary care coordination on public hospital patients. J Gen Intern Med 2000; 15(5): 329-336.

33. Halm EA, Causino N, Blumenthal D. Is gatekeeping better than traditional care? A survey of physicians' attitudes. JAMA 1997; 278(20): 1677-1681.

34. Forrest CB, Shi L, von Schrader S, Ng J. Managed care, primary care, and the patient-practitioner relationship. J Gen Intern Med 2002; 17(4): 270-277.

35. Franco SM, Mitchell CK, Buzon RM. Primary care physician access and gatekeeping: a key to reducing emergency department use. Clin Pediatr (Phila) 1997; 36(2): 63-68

36. Shea BJ, Grimshaw JM, Wells GA, et al. Development of AMSTAR: a measurement tool to assess the methodological quality of systematic reviews. BMC Med Res Methodol 2007; 7: 10. https://doi.org/10.1186/1471-2288-7-10.

37. Office for National Statistics. UK health accounts: 2015. Healthcare expenditure statistics, produced to the international definitions of the System of Health Accounts 2011. 2017. https://www.ons.gov.uk/peoplepopulationandcommunity/ healthandsocialcare/healthcaresystem/bulletins/ukhealthaccounts/2015 laccessed 18 Mar 2019).

38. Kulu-Glasgow I, Delnoij D, de Bakker D. Self-referral in a gatekeeping system: patients' reasons for skipping the general-practitioner. Health Policy 1998 45(3): 221-238.

39. Braun BL, Fowles JB, Forrest CB, et al. Which enrollees bypass their gatekeepers in a point-of-service plan? Med Care 2003; 41(7): 836-841.

40. Barrett J, Jiwa M, Rose P. Hamilton W. Pathways to the diagnosis of colorectal cancer: an observational study in three UK cities. Fam Pract 2006; 23(1): 15-19.

41. Royal College of General Practitioners. National audit of cancer diagnosis in primary care. http://www.rcgp.org.uk/policy/rcgp-policy-areas/national-auditof-cancer-diagnosis-in-primary-care.aspx (accessed 18 Mar 2019).

42. Brown S, Castelli M, Hunter DJ, et al. How might healthcare systems influence speed of cancer diagnosis: a narrative review. Soc Sci Med 2014; 116: 56-63.

43. Harris M, Frey P, Esteva M, et al. How the probability of presentation to a primary care clinician correlates with cancer survival rates: a European survey using vignettes. Scand J Prim Health Care 2017; 35(1): 27-34.

44. Hamilton W. Five misconceptions in cancer diagnosis. Br J Gen Pract 2009; DOI: https://doi.org/10.3399/bjgp09X420860

45. Lyratzopoulos G, Vedsted P. Singh H. Understanding missed opportunities for more timely diagnosis of cancer in symptomatic patients after presentation. $\mathrm{Br}$ $J$ Cancer 2015; 112(Suppl 1): S84-S91.

46. Abel GA, Mendonca SC, McPhail S, et al. Emergency diagnosis of cancer and previous general practice consultations: insights from linked patient survey data. Br J Gen Pract 2017; DOI: https://doi.org/10.3399/bjgp17X690869. 